DOI: http://dx.doi.org/10.18203/2320-1770.ijrcog20190881

Original Research Article

\title{
Perinatal outcomes in abruptio placenta
}

\section{Zenab Tambawaala, Deepali Kale*}

Department of Obstetrics and Gynecology, Nowrosjee Wadia Maternity Hospital, Mumbai, Maharashtra, India

Received: 12 December 2018

Accepted: 07 February 2019

\section{*Correspondence:}

Dr. Deepali Kale,

E-mail: deepalikale13@gmail.com

Copyright: (C) the author(s), publisher and licensee Medip Academy. This is an open-access article distributed under the terms of the Creative Commons Attribution Non-Commercial License, which permits unrestricted non-commercial use, distribution, and reproduction in any medium, provided the original work is properly cited.

\section{ABSTRACT}

Background: Abruptio placentae is an obstetric emergency where placenta completely or partially separates before delivery of the baby. It occurs approximately in one in 120 deliveries. It is an important cause of perinatal morbidity and mortality.

Methods: This was a prospective hospital-based study design conducted over a period of 2 years, in the Department of Obstetrics and Gynecology at a tertiary care hospital in Mumbai comprising of 60 cases.

Results: The incidence of abruption placentae in Present study is $0.51 \%$. Authors had perinatal mortality in $6.6 \%$ of the cases. Out of 60 cases, 2 deaths occurred in utero. Out of the remaining 58 cases, 24 babies needed NICU care, out of them, 22 went home alive and 2 had neonatal deaths. Perinatal morbidity in the form of hyperbilirubinemia, CNS depression, septicemia, neonatal anemia and neonatal DIC were noted.

Conclusions: High incidence of perinatal mortality in abruptio placentae is because of increased number of still births. In our studies, the perinatal mortality is $6.6 \%$ as compared to all other studies. This decline in perinatal mortality is due to improved obstetric care and excellent NICU facilities which are required for a majority of the cases.

Keywords: Abruptio placentae, Perinatal morbidity, Perinatal mortality

\section{INTRODUCTION}

Abruptio placentae is a serious obstetric emergency. It is defined as premature partial or complete separation of placenta in the third trimester of pregnancy before delivery of the baby. Incidence varies from $0.49 \%$ to $1.29 \%$ depending on diagnostic criteria used. ${ }^{1}$ Perinatal mortality can be as high as $25-50 \%$, but this rate has improved with better obstetric and neonatal care. Abruption can account for one in four of all perinatal deaths and thus is an important cause of perinatal morbidity and mortality. ${ }^{2}$

The primary cause of abruption is unknown but is associated with several conditions. Maternal conditions like as pregnancy-induced hypertension, chronic hypertension, PPROM, sudden uterine decompression, uterine leiomyoma, thrombophilia, folic acid deficiency and inferior vena caval occlusion contribute to the condition. External risk factors and behaviours like trauma to the abdomen, cocaine abuse and cigarette smoking also have a significant effect. A shortened umbilical cord has also been implicated. A previous history of abruption has a strong association with a recurrence rate of $5.5 \%$ to $16.6 \%$, after two abruptions, the risk increases to $25 \% .^{2}$

Vaginal bleeding is the predominant sign of placental abruption, seen in $78 \%$ of the cases presented. Uterine tenderness and abdominal pain, uterine hypertonicity, backache, fetal distress or intrauterine fetal demise may also be seen. In some cases, wide-spread extravasation of 
blood into the uterine musculature and uterine serosa is seen and is a phenomenon of uterine apoplexy, first described by Couvelair in 1912 .

Abruptio placentae occurs in about $1 \%$ pregnancies with $0.3 \%$ in pregnancy at term throughout the world with severe abruption leading to fetal death in $0.12 \%$ of pregnancies. Incidence in India varies between 1:50 to 1:500.

It may be an asymptomatic case where the diagnosis is done by the presence of a retroplacental clot post-partum $(4.5 \%)$ or presenting as sudden collapse of pregnant women with either overt or covert bleeding with fetal compromise. ${ }^{1}$

In present study, the objective was to determine the perinatal morbidity and mortality in cases of abruptio placentae in a tertiary care hospital in Mumbai.

\section{METHODS}

This was a prospective hospital-based study design conducted over a period of 2 years, from July 2010 to June 2012in the Department of Obstetrics and Gynaecology in a tertiary care hospital in Mumbai comprising of 60 cases. The study was carried out in the department of Obstetrics and Gynaecology in tertiary care hospital in, Mumbai, India. The study was conducted in a teaching and referral hospital with approximately 6,000 deliveries per year.

\section{Inclusion criteria}

- Pregnant mothers who were diagnosed with abruptio placentae.

All cases of per vaginum bleeding after 20 weeks of gestation with clinical symptoms and signs suggestive of accidental haemorrhage were included. Additionally, cases without bleeding per vaginum but suspected and confirmed by sonographic evidence as abruptio placentae were also considered. Only confirmed cases were studied. In each case, the following aspects were recorded. details of the bleeding episode (onset, amount and nature).

Chief complaint: Abdominal pain and its severity, leaking per vaginum, reduced fetal movements and maternal symptomatology (confusion, dizziness, palpitations).

Obstetric history: Previous pregnancies and details (mode, outcome, similar previous episode in earlier pregnancies, abortions and miscarriage history) and any spontaneous or induced hypertension or trauma in the current pregnancy.

On admission, maternal parameters were measured on a MEWS chart. Additionally, pallor, pedal oedema, and deep tendon reflexes were noted. Abdominal examination was done to determine the gestational age, lie, fetal heart rate localization and its pattern, uterine tenderness and hypertonicity, any scar on the abdomen and evidences of trauma to abdomen. Thus, clinical diagnosis of abruption was the main parameter in present study.

Laboratory investigations analysed included Hemoglobin levels, bleeding time, clotting time, urine albumin were done. Blood grouping, cross match, Blood urea nitrogen, serum electrolytes, blood sugars were also recorded. DIC profile was also asked for.

After maternal stabilization, urgent ultrasound was done to ascertain fetal viability, gestational age, retro-placental clots, placental localization and its distance from the os. Fetal well-being was monitored by CTGs.

Patients with abruption were managed depending on maternal condition, gestational ageof fetus, fetal viability and fetal heart rate patterns, cervical status and associated complications (like DIC, renal failure and PIH). The neonatal outcomes were followed-up with the involved neonatologists and NICU.

\section{Statistical analysis}

Entry and cleaning of data was done using MS Excel software.

\section{RESULTS}

A total of 60 cases were studied in the period from July 2010 to June 2012. The most frequent symptomatology found in present study was vaginal bleeding in $78.33 \%$ (Table 1) of the cases.

\section{Table 1: Symptomology of abruptio placenta.}

\begin{tabular}{|l|l|}
\hline Clinical Features & $\%$ \\
\hline Vaginal Bleeding & 78.33 \\
\hline Uterine tenderness & 40 \\
\hline Uterine Hypertonia & 50 \\
\hline Fetal Distress & 56 \\
\hline Backache & 13.3 \\
\hline IUFD & 3.3 \\
\hline
\end{tabular}

$40 \%$ had uterine tenderness and $50 \%$ had uterine hypertonicity. Backache was present in only $13 \%$ of our patients. Fetal distress in the form of poor beat-to-beat variability, post contraction deceleration, persistent bradycardia was noted in $34 \%$ of the cases. Two patients had still births. $58.3 \%$ of the cases presented as Grade I abruptio placentae, which is the commonest presentation in present study. $30 \%$ of the cases were of grade II and $5 \%$ of grade III. $6.6 \%$ only were of Grade 0 abruption. (Table 2).

The classification into grades of abruption was according to described by Page's classification.1 Maternal morbidity was highest in Grade 3 abruption. $66 \%$ of Grade 3 developed shock compared to $2.9 \%$ in Grade 1. 
Table 2: Distribution of grades of abruption via number of patients.

\begin{tabular}{|l|l|}
\hline Grades & $\%$ \\
\hline 0 & 7 \\
\hline 1 & 58 \\
\hline 2 & 30 \\
\hline 3 & 5 \\
\hline
\end{tabular}

All patient in Grade 3 required blood transfusion as compared to only 22\% in Grade 2 and $8.5 \%$ in Grade 1. Post-operative wound infection was higher in Grade 2 when compared to Grade 1 (Table 3).

Table 3: Maternal morbidity in abruption placenta in relation to grades of abruption

\begin{tabular}{|c|c|c|c|c|}
\hline $\begin{array}{l}\text { Maternal } \\
\text { morbidity }\end{array}$ & $\begin{array}{l}\text { Grade } 0 \\
N=4\end{array}$ & $\begin{array}{l}\text { Grade } 1 \\
\mathrm{~N}=35\end{array}$ & $\begin{array}{l}\text { Grade } 2 \\
N=18\end{array}$ & $\begin{array}{l}\text { Grade } 3 \\
\mathrm{~N}=\mathbf{3}\end{array}$ \\
\hline Shock & 0 & $2.9 \%$ & 0 & $66 \%$ \\
\hline DIC & 0 & 0 & 0 & $100 \%$ \\
\hline ARF & 0 & 0 & 0 & $33 \%$ \\
\hline Requiring BT & 0 & $8.5 \%$ & $22 \%$ & $100 \%$ \\
\hline $\begin{array}{l}\text { Wound } \\
\text { infection }\end{array}$ & 0 & $2.9 \%$ & $5.5 \%$ & 0 \\
\hline $\begin{array}{l}\text { Maternal } \\
\text { death }\end{array}$ & 0 & 0 & 0 & 0 \\
\hline
\end{tabular}

Neonatal morbidity (in the form of NICU admissions, hyperbilirubinemia, anaemia, septicaemia, RDS and DIC) were higher in the group that went on to have a vaginal delivery. $31.1 \%$ of caesarean deliveries and $66 \%$ of vaginal deliveries required NICU admission. $13 \%$ of caesarean sections and $44 \%$ of vaginal delivery in abruptio developed RDS. $3.92 \%$ cases of LSCS and $33 \%$ cases of vaginal delivery developed septicaemia. $5.88 \%$ of LSCS and $22 \%$ of vaginal delivery in abruptio placenta developed anaemia. $11 \%$ cases in the vaginal delivery group developed neonatal DIC. In conclusion, the group of neonates delivered by vaginal delivery had higher rate of morbidity when compared with the group of neonates delivered by caesarean section (Table 4 ).

Table 4: Neonatal outcomes based on mode of delivery.

\begin{tabular}{|l|l|l|}
\hline Neonatal morbidity & $\begin{array}{l}\text { Cesarean } \\
\text { section (\%) }\end{array}$ & $\begin{array}{l}\text { Vaginal } \\
\text { Delivery (\%) }\end{array}$ \\
\hline NICU admission & 31.3 & 66 \\
\hline Hyperbilirubinemia & 13 & 55 \\
\hline Anemia & 5.88 & 22 \\
\hline Septicemia & 3.92 & 33 \\
\hline RDS & 13 & 44.4 \\
\hline Neonatal DIC & 0 & 1 \\
\hline
\end{tabular}

Perinatal mortality in the form of IUFD is higher in Grade III abruption about66\%. Perinatal morbidity was seen to be highest in Grade II abruptio placentae. 83.3\% of babies in grade II required NICU care whereas in
Grade I it was $17.1 \%$ and only $50 \%$ in Grade $0.38 \%$ of Grade II abruption developed RDS whereas only 3 cases of Grade $(8.5 \%)$ of Grade I and $25 \%$ i.e. 1 case of Grade 0 abruption (Table 5).

Table 5: Perinatal morbidity in relation to grade of abruption.

\begin{tabular}{|l|l|l|l|l|}
\hline $\begin{array}{l}\text { Perinatal } \\
\text { morbidity }\end{array}$ & $\begin{array}{l}\text { Grade } \\
0(\%)\end{array}$ & $\begin{array}{l}\text { Grade } \\
1(\%)\end{array}$ & $\begin{array}{l}\text { Grade } \\
2(\%)\end{array}$ & $\begin{array}{l}\text { Grade } \\
\mathbf{2}(\%)\end{array}$ \\
\hline $\begin{array}{l}\text { NICU } \\
\text { admission }\end{array}$ & 50 & 20 & 83.3 & 0 \\
\hline $\begin{array}{l}\text { Hyperbiliru } \\
\text { binemia }\end{array}$ & 50 & 8.5 & 38 & 0 \\
\hline RDS & 25 & 8.5 & 38 & 0 \\
\hline Anemia & 0 & 5.71 & 5.5 & 0 \\
\hline Septicemia & 25 & 5.71 & 5.5 & 0 \\
\hline DIC & 0 & 0 & 5.5 & 0 \\
\hline IUFD & 0 & 0 & 0 & 6.6 \\
\hline NND & 0 & 2.9 & 5.5 & 0 \\
\hline
\end{tabular}

There is high perinatal mortality and morbidity in less than 34 weeks of gestation at presentation (Table 6). 54\% required NICU admission compared to $45.8 \%$ in more than 34 weeks requiring NICU admission. $66 \%$ of less than 34 weeks as compared to $33 \%$ more than 34 weeks developed RDS.

Table 6: Perinatal morbidity in relation to weeks of gestation.

\begin{tabular}{|l|l|l|l|l|}
\hline $\begin{array}{l}\text { Perinatal } \\
\text { morbidity }\end{array}$ & $\begin{array}{l}<0 \text { weeks } \\
(\mathbf{N}=4)\end{array}$ & $\begin{array}{l}31-34 \\
\text { weeks }\end{array}$ & $\begin{array}{l}35-37 \\
\text { weeks }\end{array}$ & $\begin{array}{l}38 \text { weeks } \\
\text { or more }\end{array}$ \\
\hline $\begin{array}{l}\text { NICU } \\
\text { admission }\end{array}$ & 3 & 10 & 8 & 3 \\
\hline $\begin{array}{l}\text { Hyperbilir } \\
\text { ubinemia }\end{array}$ & 0 & 4 & 5 & 3 \\
\hline RDS & 2 & 6 & 4 & 0 \\
\hline Anemia & 1 & 2 & 2 & 0 \\
\hline Septicemia & 2 & 1 & 1 & 0 \\
\hline DIC & 0 & 1 & 0 & 0 \\
\hline IUFD & 1 & 1 & 0 & 0 \\
\hline NND & 1 & 0 & 1 & 0 \\
\hline
\end{tabular}

Hyperbilirubinemia is highest in more than 34 weeks gestation with $66 \%$ of the cases. Anaemia developed in 3 cases in less than 34 weeks as compared to 2 cases in more than 34 weeks. Perinatal mortality in the form of IUFD and NND highest in < 34 weeks gestation ( 3 cases, $75 \%$ ). Septicaemia is highest in $<34$ weeks gestation i.e. 3 cases as compared to 1 case $(25 \%)$ in $>34$ weeks. Perinatal morbidity and mortality highest in $<2 \mathrm{~kg}$ baby. 17 cases $(70 \%)$ of $<2 \mathrm{~kg}$ required NICU admission and 7 cases $(29 \%)$ of $>2 \mathrm{~kg}$ required admission to NICU. Hyperbilirubinemia was more in $>2 \mathrm{~kg}$ babies $(75 \%)$ as compared to 3 cases in $<2 \mathrm{~kg}$ weight. RDS is more common in $<2 \mathrm{~kg}$ baby $(66 \%)$ as compared to $>2 \mathrm{~kg}$ weight (4 cases). Anaemia is more common in $<2 \mathrm{~kg}$ weight $(70 \%)$ as compared to $>2 \mathrm{~kg}$ babies. Perinatal 
morbidity is highest in $<2 \mathrm{~kg}$ weight ( 3 cases) as compared to $>2 \mathrm{~kg}$ ( 1 case). Septicemia is more common in $<2 \mathrm{~kg}$ weight ( 3 cases) as compared to 1 case in $>2 \mathrm{~kg}$ baby weight. DIC developed more in $<2 \mathrm{~kg}$ weight baby (Table 7).

Table 7: Perinatal mortality and morbidity in relation to weight in grams.

\begin{tabular}{|l|l|l|l|l|l|l|}
\hline Perinatal morbidity & $\begin{array}{l}800-999 \\
(\mathbf{N}=1)\end{array}$ & $\begin{array}{l}1000-1499 \\
(\mathbf{N}=4)\end{array}$ & $\begin{array}{l}1500-1999 \\
(\mathbf{N}=14)\end{array}$ & $\begin{array}{l}2000-2499 \\
(\mathbf{N}=18)\end{array}$ & $\begin{array}{l}2.5-2999 \\
(\mathbf{N}=20)\end{array}$ & 3000 or $>$ \\
\hline NICU admission & 0 & 4 & 13 & 3 & 3 & 1 \\
\hline Hyperbilirubinemia & 0 & 1 & 2 & 4 & 4 & 1 \\
\hline RDS & 0 & 3 & 5 & 2 & 0 & 0 \\
\hline Anemia & 0 & 0 & 4 & 1 & 1 & 0 \\
\hline Septicemia & 0 & 1 & 2 & 0 & 0 & 0 \\
\hline DIC & 0 & 0 & 1 & 0 & 0 & 0 \\
\hline IUFD & 1 & 0 & 0 & 1 & 0 & 0 \\
\hline NND & 0 & 0 & 2 & 0 & 0 & 0 \\
\hline
\end{tabular}

Table 8: One- and five-minute Apgar score in relation to mode of delivery.

\begin{tabular}{|c|c|c|c|c|c|c|c|c|}
\hline Mode & \multicolumn{4}{|c|}{ Cesarean section $\mathrm{N}=51$} & \multicolumn{4}{|c|}{ Vaginal $\mathbf{N}=9$} \\
\hline Apgar score & 7 to 10 & 4 to 6 & 1 to 3 & 0 & 7 to 10 & 4 to 6 & 1 to 3 & 0 \\
\hline $1 \mathrm{~min}$ & 34 & 5 & 2 & 1 & 5 & 3 & 0 & 1 \\
\hline $5 \mathrm{~min}$ & 50 & 2 & 0 & 0 & 6 & 0 & 0 & 0 \\
\hline
\end{tabular}

Table 9: One- and five-minute Apgar score in abruption in relation to mode of delivery.

\begin{tabular}{|c|c|c|c|c|c|c|c|c|}
\hline Mode & \multicolumn{4}{|c|}{ Cesarean section $\mathrm{N}=51$} & \multicolumn{4}{|c|}{ Vaginal $\mathbf{N}=9$} \\
\hline Apgar score & 7 to 10 & 4 to 6 & 1 to 3 & 0 & 7 to 10 & 4 to 6 & 1 to 3 & 0 \\
\hline $1 \mathrm{~min}$ & 34 & 5 & 2 & 1 & 5 & 3 & 0 & 1 \\
\hline $5 \mathrm{~min}$ & 50 & 2 & 0 & 0 & 6 & 0 & 0 & 0 \\
\hline
\end{tabular}

Caesarean section in abruptio placentae is associated with better APGAR scores at 1 min (34 cases) as compared to vaginal delivery group (5 cases). 5 cases delivered by caesarean section had Apgar score between 4-6 as compared to 3 cases of vaginal delivery ending up with low APGARs.

At 5 minutes, better APGAR scores were seen in the LSCS group as compared to vaginal delivery group (Table 8 and 9).

Table 10: Apgar scoring in relation to gestational age.

\begin{tabular}{|l|l|l|l|l|}
\hline Gestational age & $\mathbf{7 - 1 0}$ & $\mathbf{4 - 6}$ & $\mathbf{0 - 3}$ & Total \\
\hline <30 weeks & 1 & 2 & 1 & 4 \\
\hline $31-34$ weeks & 5 & 2 & 2 & 9 \\
\hline $35-37$ weeks & 18 & 9 & 1 & 23 \\
\hline 38 weeks + & 23 & 0 & 1 & 24 \\
\hline
\end{tabular}

Apgar score appears to be low in $<34$ weeks $(53.8 \%)$ as compared to $12.7 \%$ in cases $>34$ weeks. Better Apgar score seen in $82 \%$ of cases in $>34$ weeks as compared to $38 \%$ cases in $<34$ cases. Apgar score is low in cases of prematurity generally (Table 10). The perinatal morbidity and mortality (Table 11) were higher in abruptio placentae where the diagnosis to delivery interval was more than 2 hours. Perinatal morbidity in abruption placenta in relation to diagnosis to delivery interval, most of our patients were delivered in less than 2 hours.

Table 11: Perinatal morbidity in abruptio placenta in relation to diagnosis to delivery interval.

\begin{tabular}{|l|l|l|}
\hline Time & $<2$ hours & $>2$ hours \\
\hline NICU admission & $31.1 \%$ & $70 \%$ \\
\hline RDS & $11.11 \%$ & $30 \%$ \\
\hline Hyperbilirubinemia & $13 \%$ & $10 \%$ \\
\hline Sepsis & $4.4 \%$ & $10 \%$ \\
\hline Anemia & $2.2 \%$ & $30 \%$ \\
\hline
\end{tabular}

Only 10 were delivered after 2 hours. $31.1 \%$ required NICU admission when the diagnosis to delivery interval was less than 2 hours as compared to $70 \%$ when diagnosis to delivery time was more than 2 hours. $11.11 \%$ of abruption had RDS when diagnosis to delivery time was less than 2 hours where as $30 \%$ of abruption had RDS when diagnosis to delivery was more than 2 hours. $4.4 \%$ developed sepsis when diagnosis to delivery time was less than 2 hours as compared to $10 \%$ when diagnosis to delivery was more than 2 hours. $30 \%$ of 
cases developed anemia when diagnosis to delivery was more than 2 hours as compared to $2.2 \%$ cases when diagnosis to delivery was less than 2 hours.

\section{DISCUSSION}

Abruption placenta is one of the most devastating of disorders in obstetrics and it can cause great threat to mother as well as fetus. The prevalence of complicating around $2-5 \%$ pregnancies. $^{1}$ Present study of perinatal outcome due to abruption focuses attention to early diagnosis and correction of avoidable factors contributing to perinatal morbidity which will be an effective aid in raising our obstetriccare standard. The incidence of abruption placenta is $0.51 \% .^{1}$ In present study $60 \%$ of abruption occurred in primigravida. This is because of higher incidence of pre-eclampsia occurring in primigravida which is one of the predisposing factors of abruption placenta. Maximum cases of abruption were seen between 32-36 weeks. Singhal et al also reported hypertension in pregnancy in $22 \%$ of the cases in their study. $^{2}$

Sibai BM et al noted abruptio placentae in 5.6\% women with preeclampsia. ${ }^{3}$ Mandana Saadat et al studied 125 women with pre-eclampsia, abruptio placentae was noted in $8.8 \% .^{4}$ The perinatal mortality was $6.6 \%$. This decline is due to good NICU care. The studies from developing countries showed higher perinatal mortality rates due to higher number of unbooked patients. ${ }^{5}$ In their study, still birth in women with placental abruption was, significantly higher than in placenta previa. High perinatal morbidity and mortality apart from abruption placentae was due to low birth weight related to preterm birth in (65.58\%) and NICU admission in (23.65\%). DIC and acute renal injury was developed in $2.15 \%$ each in present study compared to $7 \%$ in Singhal et al. ${ }^{2} 40 \%$ of babies in present study required NICU care. $25 \%$ of babies in present study developed birth asphyxia. Fetal distress was found to be $56 \%$. Abruption placenta remains an important cause of perinatal morbidity and mortality. Causes of perinatal mortality in abruption placenta include intrauterine asphyxia because of separation or hypotension in mother due to haemorrhage or shock; prematurity because of early delivery for maternal reason; respiratory distress syndrome due to prematurity. Abruption continues to be a major cause of perinatal morbidity and was the second most common cause of perinatal mortality in collaborative perinatal project. Perinatal mortality depends on severity of abruption, gestational age at which separation of placenta occurs, birth weight. In the present study, mean age of study population wasb26.6 years. Nandonde et al reported mean age group of participants was $28.04 \pm 6.03$ years. 6 Coleman et al studied 223 cases and concluded that patient presented with abdominal pain in $158(79 \%)$ cases, vaginal bleeding in $174(87 \%)$ cases, abnormal hypertonic uterine contractions in 156 (78\%). ${ }^{7}$ Very similar to our findings which showed was vaginal bleeding in $78.33 \%$ of the cases. $40 \%$ had uterine tenderness and $50 \%$ had uterine hypertonicity. Backache was present in only $13 \%$ of our patients. Most of the patients were multigravida $119(79.33 \%)$ cases and primigravidae were $31(20.66 \%)$ in the study by Jabeen et al who observed 151 cases over a period of 1 st September 1994 to 31st August 1995.8 In present study, 60\% were primigravida. Mean gestational age was 36.37 weeks in present study. Pitaphrom et al studied 103 cases over a period of 1st January 1995 to 31st December 2004. ${ }^{9}$ They observed that the mean gestation age among studied groups was $35.3 \pm 3.4$ weeks. A study by Pariente et al was done on 1365 cases between years 1998 to $2006 .^{10}$ Patients included in the present study were having high risk factors, hypertensive disorders in pregnancy in $38.3 \%$ of the cases, premature rupture of membrane in $13 \%$ of the cases, polyhydramnios in $8 \%$ of the cases, previous pregnancy with abruptio in $6 \%$ of the cases. $85 \%$ women were found to be cephalic presentation and $15 \%$ were having breech presentation. Bhandiwad et al studied the maternal and perinatal outcome in APH.11 4 women received 4 units of packed RBC and FFP. 13 women required packed $\mathrm{RBCs}$ only. Coleman et al gave recommendations to minimise poor outcomes in abruption placentae. Blood transfusions should be carefully done under supervision to avoid transfusion reactions. ${ }^{7}$ Total of 58 live births and 2 of still birth were observed. Average number of stay in NICU was 4 days. 2 babies had NND in the NICU.

\section{CONCLUSION}

Abruption of placenta is a disastrous complication with high maternal and perinatal morbidity and mortality. The crux of management of abruption of placenta in order to improvise the outcome lies in the high clinical suspicion, early diagnosis and the better maternity unit back up with high dependency unit and neonatal unit. The awareness of risk factors for placental abruption like preeclampsia, history of previous abruption, grand multigravida, polyhydramnios must be identified, though abruption also occur in absence of risk factors. Women with any degree of antepartum haemorrhage should be triaged immediately and managed according to the severity of abruption. Timely resort to caesarean section in appropriate cases can give good perinatal outcome. Diagnosis to delivery interval should be minimizes as much as possible for better outcomes. All centres managing the same should have proper resuscitation facilities for the mother and the baby.

\section{Funding: No funding sources \\ Conflict of interest: None declared \\ Ethical approval: The study was approved by the Institutional Ethics Committee}

\section{REFERENCES}

1. Lalonde A, Daviss BA, Acosta A, Herschderfer K. Postpartum hemorrhage today: ICM/FIGO initiative 
2004-2006. Int J Gynecol Obstet. 2006;94(3):24353.

2. Singhal S, Nymphaea NS, Nanda S. Maternal and perinatal outcome in antepartum haemorrhage: A study at a tertiary care referral institute. Internet $\mathbf{J}$ Gynecol Obstet. 2008;9(2):5580.

3. Sibai BM Imitators of severe pre-eclampsia. Semin Perinatol. 2009;33(3):196-205.

4. Saadat M, Nejad SM, Habibi G, Sheikhvatan M. Maternal and neonatal outcomes in women with preeclampsia. Taiwan J Obstet Gynecol 2007;46(3):255-9.

5. Bhatia R, Kaur P, Kumari S. Rising trend of abruption placenta in a tertiary care centre: an

6. observational study. J Med Sci Clinic Res.2017;5(7):24423-30.

7. Nandonde K, Matovelo D, Massinde A, Rumanyika R. Predictors of foeto maternal outcome of patients with abruptio placentae at Bugando Medical Centre, Tanzania. J Tanz Health Res. 2016;18(1):7-9.

8. Coleman J, Srofenyo EK, Ofori EK, Brakohiapa EK, William KA. Maternal and fetal prognosis in abruptio placentae at Korle-Bu Teaching hospital, Ghana. Afr J Reprod Health. 2014;18(4):115-22

9. Jabeen M, Gul F. Abruptio placentae: Risk factors and perinatal outcome. J Pak Med 1995;18(4):66976.

10. Pitaphrom A, Suckchoroen N, Pregnancy outcomes in placental abruption,J med assoc Thai. 2006:89(10) :1572-8.

11. Pariente G, Wiznitzer A, Sergienko R, Mazor M, Holcberg G, Sheiner E. Placental abruption- critical analysis of risk factors and perinatal outcome. J Mat Fet Med 2011;24(5):698-702.

12. Bhandiwad A, Bhandiwad AA. A study of maternal and fetal outcome in antepartum haemorrhage. J Evid Based Med Hlthcare.2014;1(6):406-27.

Cite this article as: Tambawaala Z, Kale D.

Perinatal outcomes in abruptio placenta. Int J Reprod Contracept Obstet Gynecol 2019;8:1070-5. 